\title{
Depletion of $\mathrm{CD}^{+} 5^{+}$cells during acute toxoplasmosis does not significantly increase mortality in Swiss OF1 mice
}

\author{
Haroon Akbar ${ }^{1,2} /{ }^{+}$, Stéphanie Germon ${ }^{1,2}$, Patricia Berthon ${ }^{1,2}$, \\ Isabelle Dimier-Poisson ${ }^{1,2}$, Nathalie Moiré1,2 \\ 'Université François Rabelais de Tours, UMR1282 Infectiologie et Santé Publique, F-37000 Tours, France \\ ${ }^{2}$ INRA, UMR1282 Infectiologie et Santé Publique, F-37380 Nouzilly, France
}

The interleukin (IL)-2R alpha chain (CD25) is expressed on regulatory T cells (Treg), which constitute more than $85 \%$ of the $C D 25^{+} T$ cell population in a naïve mouse. CD25 is also expressed on effector T cells in mice suffering from an acute infection by the obligate intracellular protozoan parasite, Toxoplasma gondii. Lethal toxoplasmosis is accompanied by a significant loss of Treg in mice naturally susceptible to toxoplasmosis. The present study was done to explore the role of Treg cells using an anti-CD25 antibody-mediated depletion in mice naturally resistant to toxoplasmosis. Although a significant decrease in the percentage of Treg cells was observed following anti-CD25 monoclonal antibody injections, the depletion of $\mathrm{CD}_{2} 5^{+}$cells during acute toxoplasmosis did not significantly increase the mortality of Swiss OF1 mice and no significant difference was observed in the brain parasitic load between the mice in the depleted-infected and isotype-infected groups. We found no significant difference between the titres of total IgG in the sera of the mice from the two groups in the chronic phase. However, CD25+ cells depletion was followed by significantly higher levels of IL-12 in the serum of depleted mice than in that of mice injected with the isotype control antibody.

Key words: treg - depletion - toxoplasmosis

Toxoplasma gondii is an obligate intracellular protozoan parasite of worldwide significance, responsible for one of the main zoonotic diseases occurring also in developed countries. Cellular responses play an important role in protecting the host against $T$. gondii infection (Suzuki et al. 1988, Dubey 2008). In mice infected with acute toxoplasmosis, the production of interleukin (IL)-12 and of interferon (IFN)- $\gamma$ by the dendritic cells (DC) and $\mathrm{CD}^{+} \mathrm{T}$ cells respectively, triggers a $\mathrm{T}$ helper (Th)1-type protective immune response (Gazzinelli et al. 1996, Aliberti et al. 2000). The protection provided by a Th1-type response needs to be properly regulated, otherwise an excessive immune response could be deleterious for the host, as happens in case of C57BL/6 mice with acute toxoplasmosis. These mice die of an uncontrolled Th1-type immune response that causes a lethal necrotic inflammation of the intestine during the acute phase of the infection (Liesenfeld et al. 1996). Recently it has been found (Oldenhove et al. 2009) that these mice exhibit a sharp decline in the percentage of regulatory $\mathrm{T}$ cells (Treg) just before death, supporting the idea of a defective immuno-regulation. Treg cells are a subpopulation of $\mathrm{CD}^{+} \mathrm{T}$ cells and their main function is to maintain immune homeostasis and tolerance (Sakaguchi et al. 2009). They express constitutively IL-2 receptor chain

+ Corresponding author: drharoonakbar@yahoo.co.uk Received 11 April 2011

Accepted 11 December 2011 alpha, also known as CD25, a surface receptor, and the intracellular marker forkhead box-p3 transcription factor (Foxp3) (Sakaguchi et al. 2009). The CD25 expression in Treg is maintained by IL-2 (Curotto de Lafaille et al. 2004). Depending on the origin and generation, different types of Foxp3 $3^{+}$Treg cells have been described with two main subsets defined as natural Treg (nTreg) cells (developing in the thymus) and inducible Treg (iTreg) cells (developing in the periphery from conventional $\mathrm{CD}^{+} \mathrm{T}$ cells) (Belkaid 2007). Both nTreg and iTreg express CD25 and until now no specific phenotypic marker has been described to identify one from the other population. Treg cells play different roles in parasitic infections, such as in leishmaniasis and malaria (Belkaid et al. 2002, Hisaeda et al. 2004). In malaria, Treg cells have been reported either to have beneficial effects or to exacerbate disease and death (Finney et al. 2009).

A collapse of $\mathrm{CD}^{+} \mathrm{Foxp}^{+}$Treg cells has been observed in an acute and lethal model of toxoplasmosis, demonstrating the importance of Treg cells in regulating immune responses (Oldenhove et al. 2009). The regulation of the immune response in resistant strains of mice during acute toxoplasmosis remains to be explored, as only a few contradictory reports, in terms of mortality, exist so far (Oldenhove et al. 2009, Tenorio et al. 2010, Morampudi et al. 2011). The level of CD4 $4^{+} \mathrm{Foxp}^{+}$Treg cells appears to be correlated with the resistance of mice to acute toxoplasmosis (Oldenhove et al. 2009, Couper et al. 2009, Tenorio et al. 2010, 2011). CD4 ${ }^{+} \mathrm{Foxp}^{+}$Treg cells do not decrease significantly in a toxoplasmosis-resistant mouse model (BALB/c) (Oldenhove et al. 2009, Tenorio et al. 2011) whereas a very marked reduction in the percentage of these cells does occur in an acute toxoplasmosis-susceptible mouse model (C57/BL6) (Oldenhove et al. 2009). 
Different approaches have been used to analyse Treg cell functions. These have included the depletion of CD25 ${ }^{+}$Treg cells using anti-CD25 monoclonal antibody (mAb) (Hisaeda et al. 2004, Couper et al. 2009, Tenorio et al. 2010). The depletion mechanism is not fully understood, but anti-CD25 treatment caused the downregulation or shedding of CD25 marker on Treg cells and reduced the percentage of Foxp3 $3^{+}$cells (Kohm et al. 2006, $\mathrm{McNeill}$ et al. 2007). One study describes the role of Fc $\gamma$ $\mathrm{RIII}^{+}$phagocytes in anti-CD25 mAb mediated depletion of Treg cells (Setiady et al. 2010).

In the work reported here, we studied the effects of anti-CD25 mAb-mediated depletion of CD25 ${ }^{+}$cells in Swiss OF1 mice (which are naturally resistant to toxoplasmosis) during acute infection with strain $76 \mathrm{~K}$, a type-II strain of T. gondii. Although a significant reduction of $\mathrm{CD} 25^{+}$Treg cells was observed in both spleen and mesenteric lymph nodes (MLN) on day 6 post-infection (p.i.) with significant production of serum IL-12, no significant difference was observed in mortality or brain parasitic load in the mice receiving anti-CD25 mAb compared to those receiving isotype control $\mathrm{mAb}$. At the same time, we did find a significant increase in $\mathrm{CD} 25^{+}$effector T cells (Teff) cells in mice receiving isotype control $\mathrm{mAb}$. On the other hand, no significant difference was found for the $\mathrm{CD} 4^{+} \mathrm{Foxp} 3^{+} \mathrm{CD} 25^{+}$ Treg/CD4 $4^{+}$Foxp3 ${ }^{-} \mathrm{CD} 25^{+}$Teff ratio between mice from the infected groups injected with either anti-CD25 mAb or isotype control $\mathrm{mAb}$. Hence anti-CD25 mAb mediated depletion of $\mathrm{CD} 25^{+}$cells did not significantly increase the mortality of a naturally resistant strain (Swiss OF1) of mouse during acute infection with $T$. gondii.

\section{MATERIALS AND METHODS}

Mice - Six-eight week old Swiss OF1 female mice were purchased from Janvier (France) and were kept in the animal house of the University of Tours. The mice were given food and water ad libitum. The infected animals were observed for the onset of clinical signs or symptoms daily (e.g. coat, response to external stimuli and physical activity in the cage) until euthanized.

Parasites and infections - T. gondii strain $76 \mathrm{~K}$ was used to infect the mice. The 76K strain is being maintained in female $\mathrm{CBA} / \mathrm{J}$ mice. Every month, the naïve $\mathrm{CBA} / \mathrm{J}$ mice are infected orally with 50 cysts of this strain collected from the brain of a $\mathrm{CBA} / \mathrm{J}$ mouse in chronic phase of the infection.

Brains containing the cysts were homogenised in RMPI-1640 medium (Dutscher, Brumath, France) and the cysts were counted under microscope. Swiss OF1 mice were orally infected with 50 cysts.

Antibody treatments - The mAb used against the $\mathrm{CD} 25$ was a rat IgG1 (PC61 clone, ATCC). The isotype control rat IgG1 was obtained from the CRL1912 hybridoma (a kind gift of Dr Laleh Majlessi, Institut Pasteur, Paris, France). Both antibodies were purified by ammonium sulphate $(40 \%)$ precipitation from the supernatants of the hybridoma culture. After precipitation, the supernatant was extensively dialysed against a phosphate buffered saline (PBS) solution. The concentrated and dialysed supernatants of hybridomas were purified using
HiTrap Protein-G HP columns (GE Healthcare) following the manufacturer's recommendations. The purified antibodies were assayed for protein concentration by the micro-BCA technique using a commercial kit (SigmaAldrich from Servilab, Le Mans, France) containing purified bovine serum albumin (BSA) as standard protein.

The mice were depleted of $\mathrm{CD} 25^{+}$cells by the intraperitoneal injection of anti-CD25 antibody (500 $\mu \mathrm{g}$ per mouse per administration) on days $-1,0,3$ and 6 of infection. The isotype-control group was also injected at the same time and same dose as the anti-CD25 mAb treated group.

Blood leucocytes, spleen cells and MLN cells - Blood was collected from the medial canthus of the mouse eyes in anti-coagulant [ethylenediamine tetraacetic acid (EDTA) or heparin]-coated blood collection tubes and mixed thoroughly. The red blood cells were lysed twice with $5 \mathrm{~mL}$ of lysis buffer $\left(0.15 \mathrm{M} \mathrm{NH}_{4} \mathrm{Cl}, 1.0 \mathrm{M} \mathrm{KHCO}_{3}\right.$, $0.1 \mathrm{mM} \mathrm{Na} \mathrm{EDDT}_{2} \mathrm{pH} 7.3$ ) for $2 \mathrm{~min}$ at room temperature. The lysis reaction was stopped by adding $20 \mathrm{~mL}$ of RPMI-1640 supplemented with 5\% foetal calf serum (FCS) (Dutscher, Brumath, France).

Mice were euthanized by cervical dislocation on day 6 p.i. Spleens and MLN were collected and cell suspensions were prepared as previously described (Ismael et al. 2003). The cells were stained with specific antibodies in 96 -well plates with $5 \times 10^{5}$ cells/well.

Flow cytometry - The $\mathrm{CD} 4^{+} \mathrm{CD} 25^{+}$cells and $\mathrm{CD} 4^{+} \mathrm{CD} 25^{+} \mathrm{Foxp}^{+}$cells were analysed by flow cytometry using FACScalibur (BD Biosciences, Le Pont de Claix, France). Anti-mouse CD4-(H129-19) FITC, antimouse CD25-PE (7D4) monoclonal labelled antibodies and their corresponding isotype controls were obtained from BD Biosciences (Le Pont de Claix, France). Cells were incubated for $15 \mathrm{~min}$ at $4^{\circ} \mathrm{C}$ for saturation in 200 $\mu \mathrm{L}$ of $4 \%$ BSA (Sigma) prepared in PBS and then stained in the same medium. For Foxp3 staining, the cells were labelled using the Foxp3 staining set (clone FJK 16s) purchased from eBiosciences (Clinisciences, Montrouge, France) according to the recommended protocols. For each sample, at least 50,000 events were acquired.

ELISA and brains cyst load - Cytokine and chemokine levels [IFN- $\gamma$, IL-10, IL-12 p70, monocyte chemoattractant protein (MCP-1)] were quantified from mouse serum by ELISA using OptEIA kits (BD Biosciences, Le Pont de Claix, France) following the manufacturer's recommendations.

Serum samples were collected six weeks p.i. before the mice were euthanized for the detection of toxoplasma specific IgG. The titres were calculated as described previously (Ismael et al. 2003).

The brains were collected in $5 \mathrm{~mL}$ of RPMI-1640 and homogenised with a potter. The number of parasite cysts in the homogenate was calculated under microscope by 10 counts per mouse using $10 \mu \mathrm{L}$ of homogenate for each count.

Statistics - The two-tailed Mann-Whitney test, Student's $t$ test and Kruskall Wallis test were used to compare the values. $\mathrm{p}<0.05$ was considered significant. 
Ethics - All experiments were performed in accordance with the guidelines on animal experimentation of the Université François Rabelais de Tours, France.

\section{RESULTS}

Clinical signs and survival of mice acutely infected with T. gondii after $C D 25^{+}$cell depletion - Mice were divided into two groups: one treated with the anti-CD25 $\mathrm{mAb}$ (anti-CD25 group) and the other treated with the isotype control $\mathrm{mAb}$ (control $\mathrm{mAb}$ group) before and during infection with $T$. gondii. Clinical signs and survival of the mice were monitored to find out whether the anti-CD25 mAb administration increased the susceptibility of the mice to acute toxoplasmosis. We confirmed that the anti-CD25 $\mathrm{mAb}$ injection induced significant depletion (by about $60 \%$ ) of $\mathrm{CD} 25^{+}$cells in the blood of the naïve mice (data not shown). All the mice in both infected groups became sick at day 6 p.i. and developed a ruffled coat that lost its sheen and became dull in appearance. This continued till 11 days p.i. On day 13 p.i, all the mice in the control $\mathrm{mAb}$ group started to recover, whereas those in the anti-CD25 group still displayed
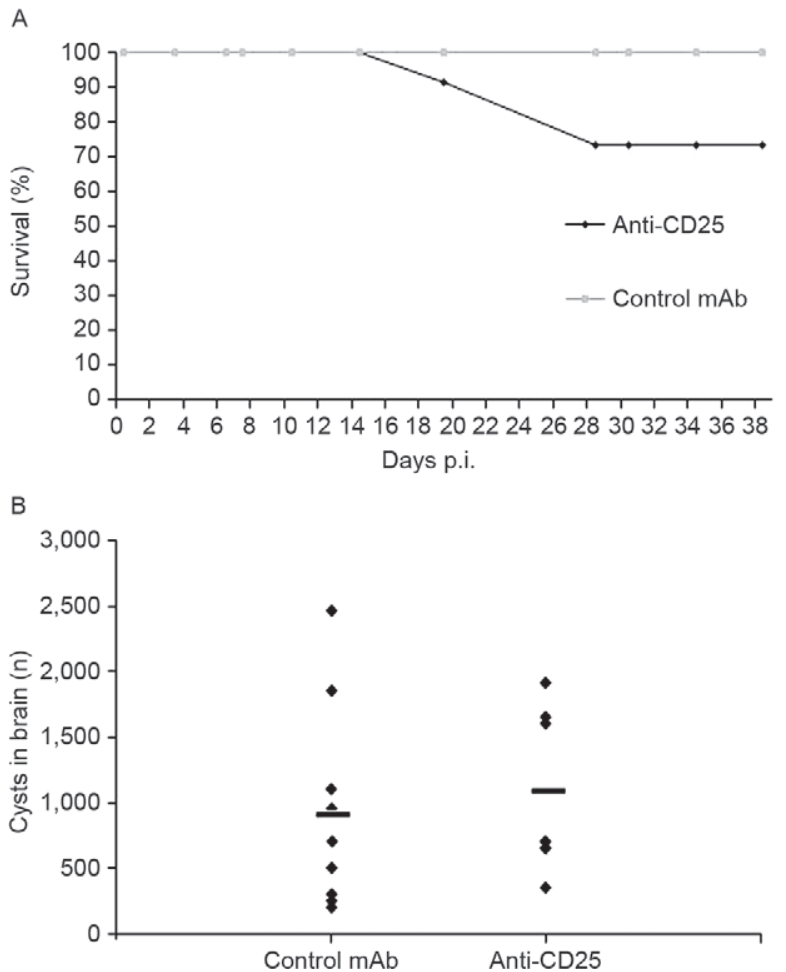

Fig. 1A: survival of mice injected with anti-CD25 or with isotype control antibody and infected $24 \mathrm{~h}$ after the first antibody injection. $\mathrm{N}=11$ for the anti-CD25 group and $\mathrm{n}=10$ for the control monoclonal antibody $(\mathrm{mAb})$ group. The $\chi^{2}$ test with the Yates correction was used to compare the mortality between the two groups. The difference between the two groups was non-significant $(p=0.2463)$. The experiment was repeated twice with similar results; B: the brain cyst load on day 38 post-infection (p.i.) in mice injected with anti-CD25 or with isotype control antibody. $\mathrm{N}=8$ for the anti-CD25 group and $\mathrm{n}=10$ for the control $\mathrm{mAb}$ group. A two-tailed Mann-Whitney test was used to compare the groups. The difference was not significant $(\mathrm{p}>0.05)$. The graph is representative of two similar experiments. clinical signs. The survival of the mice was followed up to six weeks p.i. Twenty-seven percent mortality was observed in the anti-CD25 group from day 19-28 p.i. (Fig. 1A). The difference in mortality between the groups was not significant $(\mathrm{p}=0.2463)$.

The parasite load was estimated in mice brains during the chronic phase of infection at six week p.i. The depletion of $\mathrm{CD}_{2} 5^{+}$cells did not cause any significant difference in the number of tissue cysts in the brains of the anti-CD25 mice compared to those in the control $\mathrm{mAb}$ group $(926 \pm 733$ cysts in the control mAb group vs. $1,026 \pm 592$ cysts in the anti-CD25 group) (Fig. 1B).

Serum was collected from the mice in the sixth week p.i. and used to determine the total IgG titre. In both experiments, all groups had a high IgG titre, but no significant difference was observed between the titres of total $\operatorname{IgG}$ antibodies in the sera of mice injected with either the anti-CD25 antibody or the isotype control mAb (Table I).

Increase in the percentage of $C D 4^{+} C D 25^{+} T$ cells among the $C D 4^{+}$blood cells during acute toxoplasmosis - To find out whether acute infection caused an increase in the percentage of $\mathrm{CD} 25^{+}$cells, we performed a kinetic study to determine the percentage of $\mathrm{CD} 4{ }^{+} \mathrm{CD} 25^{+}$cells among the circulating $\mathrm{CD} 4^{+}$cells in the blood of the mice (Fig. 2A) after infection. A significantly higher percentage of $\mathrm{CD} 4^{+} \mathrm{CD} 25^{+}$cells $(5.23 \pm 1.92$ before infection vs. $12.07 \pm 2.59$ after infection) was found at day 3 p.i. (p $<0.05$ ). At day 6 p.i., the percentage of $\mathrm{CD} 4^{+} \mathrm{CD} 25^{+}$cells in the blood of the infected mice was not significantly different from that before infection.

Effect of infection and depletion on the $C D 4^{+}$and $C D 4^{+} C D 25^{+} T$ cell population - We further identified the depleted population after the anti-CD25 mAb injections. For this purpose, the mice were euthanized at day 6 p.i. Hypertrophy of the spleens and MLNs was observed in both infected groups of mice. The total number of splenocytes was significantly higher in both infected groups than in the naïve mice (Fig. 2B). The total number of MLN cells was increased in both infected groups; in the control $\mathrm{mAb}$ group this difference was statistically significant, whereas in the anti-CD25 group it was not (Fig. 2C).

\section{TABLE I}

Total serum $\operatorname{IgG}$ titres $^{a}$ during the chronic phase of infection

\begin{tabular}{lcc}
\hline Experiment & $\begin{array}{c}\text { Control } \mathrm{mAb}^{b} \\
(\text { mean } \pm \mathrm{SD})\end{array}$ & $\begin{array}{c}\text { Anti-CD25 } \\
(\text { mean } \pm \mathrm{SD})\end{array}$ \\
\hline I & $17.64 \pm 0.57^{d}\left(\mathrm{n}^{e}=10\right)$ & $18.08 \pm 0.53^{d}\left(\mathrm{n}^{e}=9\right)$ \\
II & $16.74 \pm 1.60^{d}\left(\mathrm{n}^{e}=10\right)$ & $16.39 \pm 1.04^{d}\left(\mathrm{n}^{e}=8\right)$ \\
\hline
\end{tabular}

$a$ : the antigen specific antibody titre expressed as $\log 2$ of the reciprocal of the highest dilution producing an optical density that was 2.5 fold greater than that of the serum of the control mice; $b, c$ : Toxoplasma gondii infected groups injected with isotype control and anti-CD25 monoclonal antibody (mAb), respectively; $d$ : differences were found non-significant by non-parametric Mann-Whitney test with $\mathrm{p}>0.05$; $e$ : number of mice; SD: standard deviation. 
At day 6 p.i, the number of $\mathrm{CD}^{+}$spleen cells was also higher in both infected groups (Table II). This difference in number was significant in the control $\mathrm{mAb}$ group, but not in the anti-CD25 group for spleen and not significant in either group for MLN compared to the naïve group (Table II).

Despite the increased number of $\mathrm{CD}^{+}$cells in spleens and MLNs of infected groups, their percentage was significantly lower in both organs compared to that in naïve mice (Table II).
We next examined $\mathrm{CD} 4{ }^{+} \mathrm{CD} 25^{+} \mathrm{T}$ cells after the anti$\mathrm{CD} 25 \mathrm{mAb}$ treatment. A significantly greater number of $\mathrm{CD} 4^{+} \mathrm{CD} 25^{+} \mathrm{T}$ cells was found in both spleen and MLN of the control $\mathrm{mAb}$ group compared to the naïve mice (Fig. 2D, F). The number was not significantly greater in the anti-CD25 group than that in either the naivve or the control mAb group. Similarly, the percentage of $\mathrm{CD} 4^{+} \mathrm{CD} 25^{+} \mathrm{T}$ cells was significantly lower in both the spleen and MLN of the anti-CD25 group than in the control mAb group (Fig. 2E, G). As CD4 $4^{+} \mathrm{CD} 25^{+} \mathrm{T}$ cells
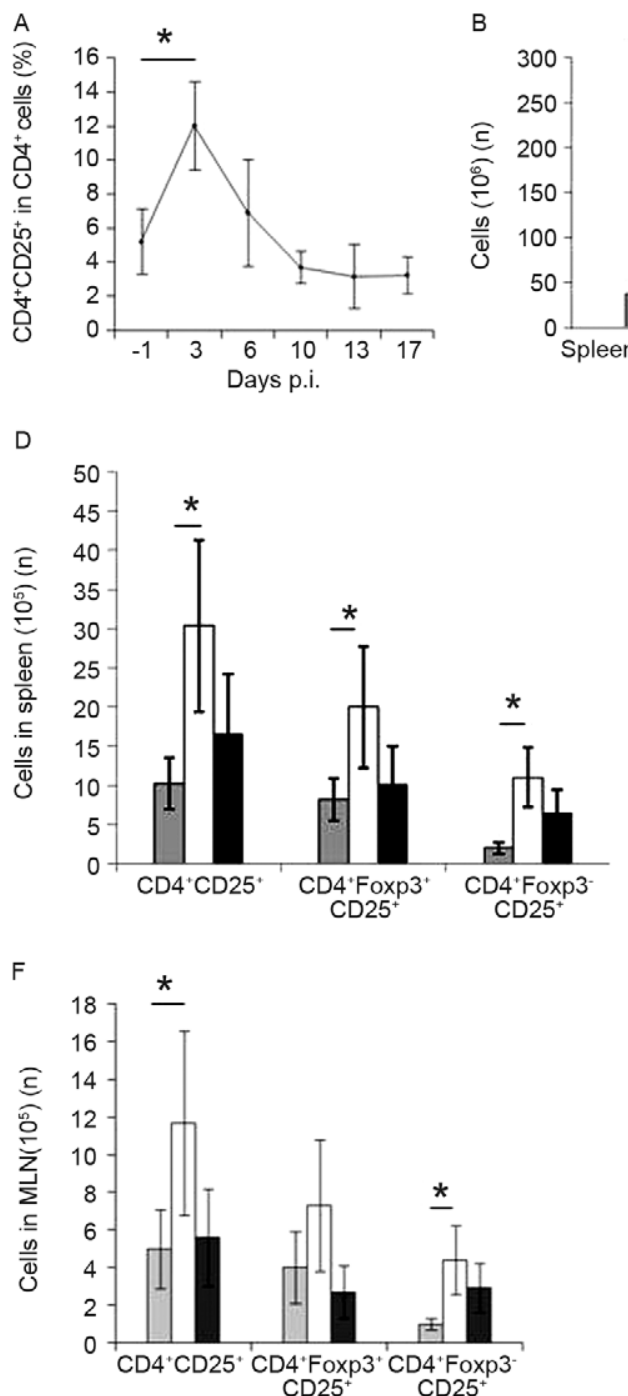
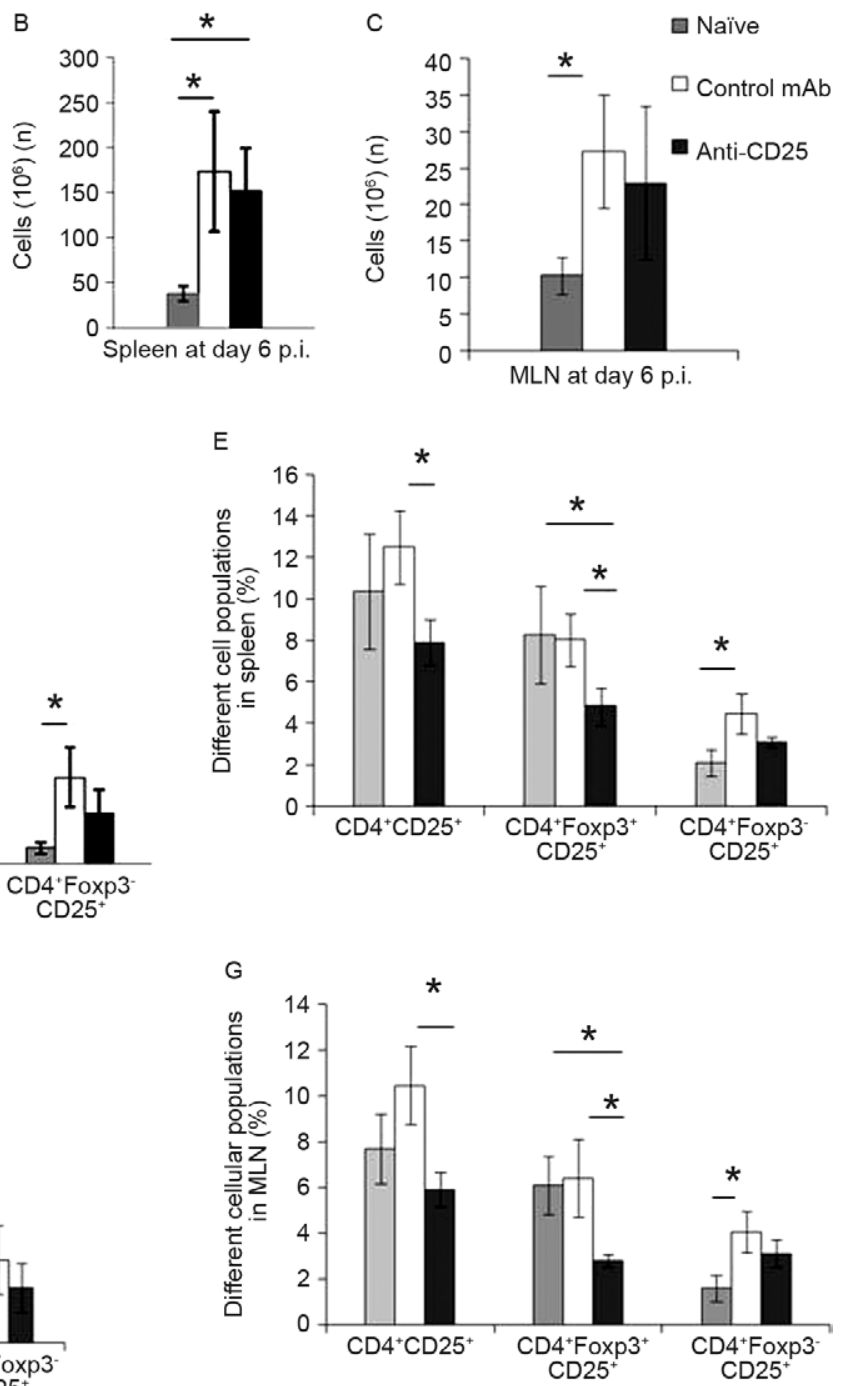

Fig. 2A: data from only infected mice, without pre-treatment. Swiss OF1 mice were infected orally with 50 cysts of Toxoplasma gondii. The blood of mice was collected during acute infection at days 3, 6, 10, 13 and 17 post-infection (p.i.). The percentage of CD4 $4^{+} \mathrm{CD} 25^{+}$cells was calculated in the $\mathrm{CD}^{+}$cells of the lymphocyte population. The graph represents the average values found on each test day, along with the standard deviations (SD). $\mathrm{N}=11$ for naïve mice and $\mathrm{n}=5$ for each day p.i. The Kruskall Wallis test was used to compare the results. Asterisk means a significant difference $(\mathrm{p}<0.05)$; B-G: data from pre-treated and infected mice. The graphs represent the average values along with the SD of the total number of cells in spleen (B) and in mesenteric lymph nodes (MLN) (C). The Kruskall-Wallis test was used to determine the difference between three groups. Asterisk means a significant difference $(\mathrm{p}<0.05) . \mathrm{N}=5$ for each group. The graphs represent the average values along with the SD of the total number (in spleen/MLN) and percentages (among CD4 ${ }^{+}$) of $\mathrm{CD}^{+} \mathrm{CD} 25^{+}$cells, $\mathrm{CD} 4^{+}$forkhead box-p3 transcription factor (Foxp3 $3^{+}$CD25 $5^{+}$regulatory T cells (Treg) and CD4 ${ }^{+}$Foxp3-CD25+ effector T cells (Teff) cells in spleen (D, E) and in MLN (F, G). The Kruskall-Wallis test was used to determine the differences between the three groups. The experiment was done once. Asterisk means a significant difference $(\mathrm{p}<0.05)$. $\mathrm{N}=5$ for each group; $\mathrm{mAb}$ : monoclonal antibody. 
include both $\mathrm{CD} 25^{+}$Treg and CD25 $5^{+}$Teff cells, we used Foxp3, to differentiate between $\mathrm{CD} 4{ }^{+} \mathrm{Foxp}^{+} \mathrm{CD} 25^{+}$Treg and $\mathrm{CD} 4^{+}$Foxp3-CD25+ ${ }^{+}$Teff cells.

Effect of infection and $C D 25^{+}$-cell depletion on $C D 4^{+}$Foxp $3^{+} C D 25^{+}$Treg, $C D 4^{+}$Foxp $3^{-} \mathrm{CD} 25^{+}$Teffcells and on $\mathrm{CD} 4^{+} \mathrm{Foxp}^{+} \mathrm{CD} 25^{+}$Treg $/ \mathrm{CD} 4^{+}$Foxp $3^{-} \mathrm{CD} 25^{+}$Teff ratio - A significantly greater number of $\mathrm{CD} 4^{+} \mathrm{Foxp} 3^{+} \mathrm{CD} 25^{+}$ Treg cells was observed in the spleens of the control $\mathrm{mAb}$ group compared to the naïve group (Fig. 2D). No significant difference was observed for the anti-CD25 group compared to either of the other groups (Fig. 2D). Similarly, more Treg cells, although the difference was not significant, were observed in MLN in the control $\mathrm{mAb}$ group than in the naïve group. The number of Treg was not significantly different in the anti-CD25 group compared to either the naïve or control mAb group (Fig. 2F).

A significantly lower percentage of Treg cells was observed in the anti-CD25 group than in either the naïve group or the control $\mathrm{mAb}$ group in both spleen and MLN at day 6 p.i. (Fig. 2E, G). No significant difference was observed between the percentages of Treg in the control $\mathrm{mAb}$ group and the naïve group. This was the case for both spleen and MLN (Fig. 2E, G).

A significantly greater number and percentage of CD4 ${ }^{+}$Foxp3 ${ }^{-} \mathrm{CD} 25^{+}$Teff cells was observed at day 6 p.i. in the control $\mathrm{mAb}$ group than in the naïve mice. This was observed in both spleen and MLN (Fig. 2D-G). No significant difference in either the number or percentage was observed in the anti-CD25 group for either spleen or MLN compared to the naïve or control groups.

The $\mathrm{CD}^{+}{ }^{+} \mathrm{Foxp}^{+} \mathrm{CD}^{\mathrm{C}} 5^{+}$Treg/CD4 ${ }^{+}$Foxp3 ${ }^{-\mathrm{CD}} 25^{+}$ Teff ratio was lower in the anti-CD25 and control mAb groups than in the naïve group and this was observed for both spleen and MLN. The value in the anti-CD25 group was significantly lower than in the naïve group. There was no significant difference between the naïve and control $\mathrm{mAb}$ groups or between the control $\mathrm{mAb}$ and anti-CD25 groups (Fig. 3A).

$C D 25^{+}$cell depletion did not significantly reduce the production of the cytokines, IFN- $\gamma, I L-10$ and chemokine

\section{TABLE II}

Total number and percentage of $\mathrm{CD}^{+}$cells in spleen and mesenteric lymph nodes (MLN) at day 6 post-infection

\begin{tabular}{|c|c|c|c|c|}
\hline Organ & & $\begin{array}{l}\text { Naïve mice } \\
(\text { mean } \pm \mathrm{SD})\end{array}$ & $\begin{array}{l}\text { Control } \mathrm{mAb}^{a} \\
(\text { mean } \pm \mathrm{SD})\end{array}$ & $\begin{array}{l}\text { Anti-CD25 } \\
(\text { mean } \pm \mathrm{SD})\end{array}$ \\
\hline \multirow[t]{2}{*}{ Spleen } & Number $\left(10^{6}\right)$ & $9.9 \pm 2.6$ & $24.3 \pm 8.3^{c}$ & $20.5 \pm 8.1$ \\
\hline & $\%$ & $26.2 \pm 4.4$ & $14.4 \pm 2.8^{c}$ & $13.4 \pm 1.5^{c}$ \\
\hline \multirow[t]{2}{*}{ MLN } & Number $\left(10^{6}\right)$ & $6.4 \pm 1.6$ & $11 \pm 3.6$ & $9.6 \pm 4.4$ \\
\hline & $\%$ & $62.3 \pm 2$ & $40 \pm 4.2^{c}$ & $41.3 \pm 4.9^{c}$ \\
\hline
\end{tabular}

$a, b$ : Toxoplasma gondii infected mice injected with isotype control and anti-CD25 monoclonal antibody (mAb), respectively; $c$ : differences were found significant against naïve group by non-parametric Kruskall Wallis test with $\mathrm{p}<0.05$; SD: standard deviation.
MCP-1, but did cause a significant increase in IL-12 production - Although a significant reduction in the percentage of Treg cells was observed at day 6 p.i. in the anti-CD25 group, no difference in the parasitic load of the brains was observed. We therefore determined the levels of the chemokine MCP-1 and cytokines IL-12, IFN- $\gamma$ and IL-10 in the sera of the mice at day 6 p.i. There was a significant production of both MCP-1 (Fig. 3B) and IFN- $\gamma$ (Fig. 3D) in both the control $\mathrm{mAb}$ and anti-CD25 groups compared to the naïve group. The production of IL-10 was significantly greater in the control $\mathrm{mAb}$ group, but not in the anti-CD25 group, than in the naïve mice (Fig. $3 \mathrm{E})$. No significant difference was noted in the level of IL-12 production between the naïve mice and those in the control mAb group (Fig. 3C).

Similarly no significant differences were found between the control $\mathrm{mAb}$ and anti-CD25 groups for the levels of MCP-1, IFN- $\gamma$ and IL-10 (Fig. 3B, D, E). The only difference was found for IL-12 production, which was significantly greater in the anti-CD25 group than in either the naïve group or the control mAb group (Fig. 3C).

\section{DISCUSSION}

One of the main objectives of this work was to study the role of Treg cells during acute toxoplasmosis in a resistant out-bred mouse strain. The parasite multiplies in the intestine after an oral infection (the most common natural route of infection) and then it spreads to different organs during the acute phase of the infection. It has been shown that tachyzoites appeared in the brain between six-eight days after infection, however, the cysts are only detectable from four weeks after the infection.

The present study was done in a naturally-resistant mouse model, Swiss OF1 mice, using a type-II strain (76K) of $T$. gondii administered by oral route. The oral route is a natural route of infection for most of animal and human infections. Swiss OF1 mice are an out-bred mouse strain displaying individual variability of infection resistance. The results observed with this strain can readily be extrapolated to farm animals and possibly also to human (Rai et al. 2009).

Treg cells were depleted using anti-CD25 mAb, a classical technique used in several other models of infection (Hisaeda et al. 2004, Couper et al. 2007, Kotner $\&$ Tarleton 2007). In the current study, anti-CD25 mAb efficiently depleted $\mathrm{CD} 25^{+}$cells (by about $60 \%$ in blood, spleen and MLN cells) in the naive mice (unpublished observations) in a manner comparable to that reported earlier (Couper et al. 2007, Kotner \& Tarleton 2007, Morampudi et al. 2011). We observed that about $84 \%$ of the $\mathrm{CD} 4^{+} \mathrm{CD} 25^{+}$cells comprise CD $4^{+} \mathrm{CD} 25^{+} \mathrm{Foxp}^{+}$Treg cells in naïve mice (data not shown) and hence are the main target of anti-CD25 mAb mediated depletion in naïve mice (Supplementary data). Anti-CD25 mAb caused also a significant reduction (about 40\%) in the percentage and number of $\mathrm{CD} 4{ }^{+} \mathrm{CD} 25^{+}$cells in the spleen and MLN of the infected mice. In infected mice, anti-CD25 mAb administration preferentially targets Foxp $3^{+}$Treg cells with $40-57 \%$ depletion in spleen and MLN respectively, as described in the work of Morampudi et al. (2011) and Tenorio et al. (2011). However, no significant difference 
was found in the Treg/Teff ratios between both infected groups injected during acute infection and consistent with this, no significant differences were observed between the same two groups for mortality, brain parasitic load or total serum IgG levels. The depletion during acute phase using anti-CD25 is not sustained for a long time after the last antibody injection. No significant differences were observed in the percentage of $\mathrm{CD} 4^{+} \mathrm{CD} 25^{+}$ and $\mathrm{CD}^{+}{ }^{+} \mathrm{Foxp}^{+}$splenocytes and MLN cells at day 34 p.i. (unpublished observations) in the mice depleted during acute phase. Similarly, injection of anti-CD25 during chronic phase of the infection (from day 29 p.i.) also showed no effect on the mortality, as well as on the brain parasitic load (unpublished observations) like also described by Couper et al. (2009).

In one experiment, one out of 11 mice died and two mice were euthanized due to loss of more than $20 \%$ of their bodyweight. These two mice were found to be immunosuppressed as they displayed spleen atrophy (data not shown). This was probably due to the immunosuppressive effects of anti-CD25 mAb (Waldmann 2007). However, no significant difference in mortality was observed in OF1 mice following injections of anti-CD25 $\mathrm{mAb}$. This is consistent with data reported by Oldenhove
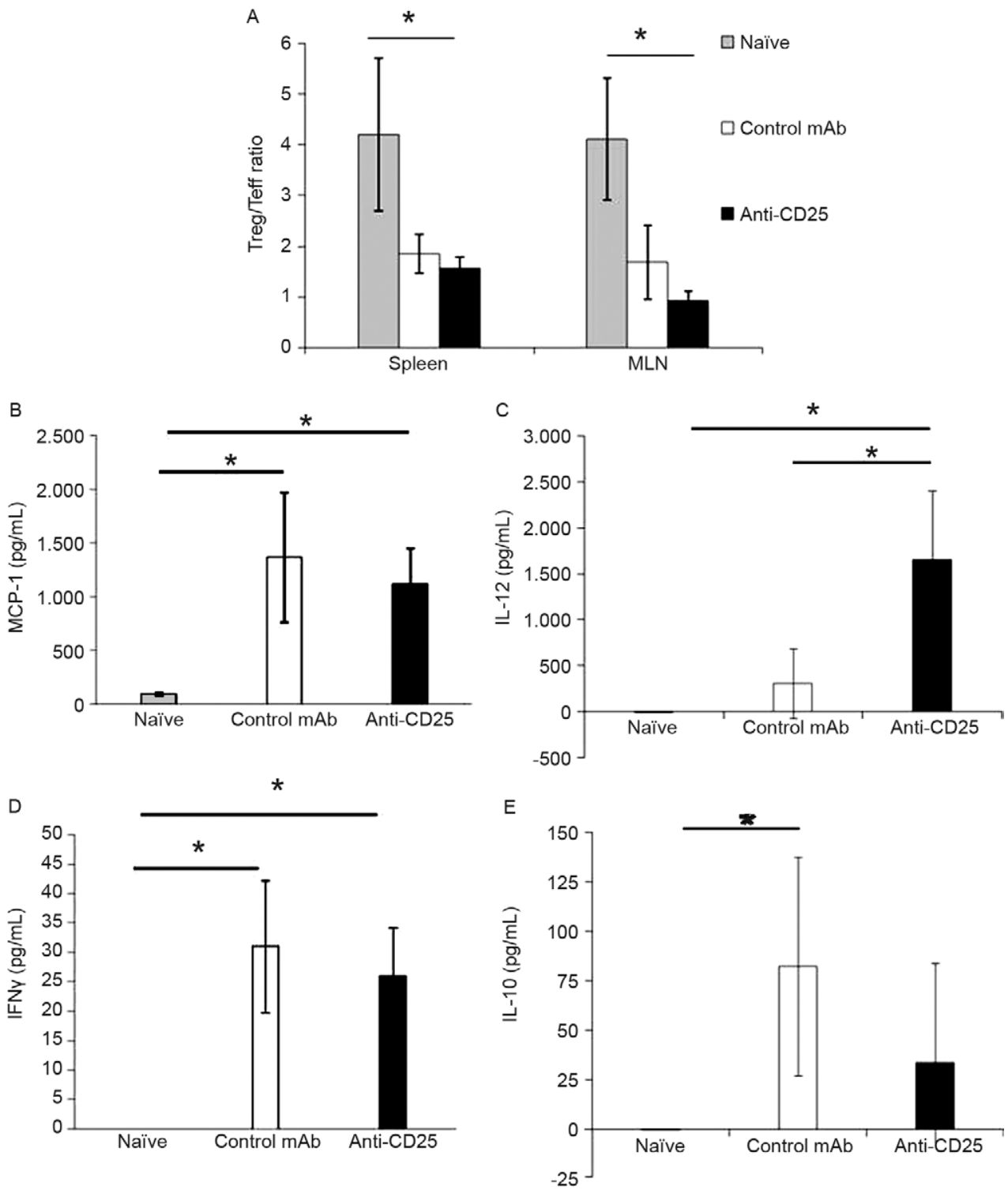

Fig. 3A: the graphs represent the regulatory $\mathrm{T}$ cells (Treg)/effector $\mathrm{T}$ cells (Teff) ratio in spleen and mesenteric lymph nodes (MLN). The Kruskall-Wallis test was used to determine the difference between the three groups. Asterisk means a significant difference $(p<0.05)$. N $=5$ for each group. Serum monocyte chemoattractant protein (MCP-1) (B), interleukin (IL)-12 (C), interferon (IFN) $\gamma$ (D) and IL-10 (E) levels in mice before infection or on day 6 post-infection in mice injected with anti-CD25 or isotype control antibody determined by ELISA. $\mathrm{N}=10$ for naïve mice, $n=11$ for the anti-CD25 group and $n=10$ for the control monoclonal antibody (mAb) group. The Kruskall-Wallis test was used to compare the groups. Asterisk means a significant difference $(p<0.05)$. Similar results were obtained in two experiments. 
et al. (2009) and Morampudi et al. (2011) using BALB/c resistant mice, but not with the findings of Couper et al. (2009) in susceptible C57BL/6 mice.

No significant difference was found in the brain parasitic load between infected OF1 mice receiving anti-CD25 $\mathrm{mAb}$ or the isotype control antibody, which conflicts with the findings of Couper et al. (2009) and Morampudi et al. (2011), who observed a rise in number of cysts in brain after the depletion of $\mathrm{CD} 25^{+}$cells. The significant difference in brain parasitic load observed by Couper et al. (2009) might be due to the facts that Couper et al. (2009) used a naturally susceptible mouse strain (C57BL/6) and showed a more pronounced effect of anti-CD25 mAb on effector $\mathrm{T}$ cells during acute toxoplasmosis. Similarly, Tenorio et al. (2011) reported that anti-CD25 mAb has more pronounced effect on effector T cells in acute toxoplasmosissusceptible mouse model (C57BL/6).

Morampudi et al. (2011) observed a higher parasitic load in the brain of BALB/c mice after depletion with PC61. The discrepancy between the study of Morampudi et al. (2011) and the present work, in term of parasitic load, could be due of the kinetic of injections of PC61 and the difference in mouse strain.

Consistent with the lack of effect on parasitic load, anti-CD25 administration had no effect on circulating IFN- $\gamma$ level in our experimental condition. Whereas Couper et al. (2009) observed that anti-CD25 mAb treatment leads to reduced circulating IFN- $\gamma$ level, consistent with the preferential depletion of Teff cells in the C57BL/6 mice. On the contrary, Morampudi et al. (2011) observed increased IFN- $\gamma$ level and high parasite burden after antibody treatment of BALB/c mice consistent with the preferential depletion of Treg cells in these mice (Tenorio et al. 2011). In our experiments, although antiCD25 mAb administration preferentially targets Treg no significant difference, in the Treg/Teff ratio was found between the two infected groups given anti-CD25 mAb or the control $\mathrm{mAb}$, respectively. This may account for the similar IFN- $\gamma$ level in both groups.

IFN- $\gamma$ is produced by $\mathrm{CD} 4^{+}$Foxp $3{ }^{-} \mathrm{CD} 25^{+}$Teff cells (Couper et al. 2009) and natural killer cells (Gazzinelli et al. 1993) during acute toxoplasmosis and is responsible for the control of parasite replication. The IFN- $\gamma$ production is largely IL-12-dependent (Gazzinelli et al. 1993, 1994a, b, Khan et al. 1994). CD25+ cell depletion induced the significant production of IL-12 that is not followed in our experiment by increased serum IFN- $\gamma$ level in depleted infected mice. IL-12 is produced by DC (Aliberti et al. 2000) and macrophages (Robben et al. 2004). Treg cells exert their regulatory function on effector $\mathrm{T}$ cells and also on antigen presenting cells (APC) (Mahnke et al. 2007). Cytotoxic T lymphocyte associated antigen- 4 of Treg cells can prevent the maturation (by down-regulation of CD80/86) of DC by engaging with the B7 of these cells (Mahnke et al. 2007, Grainger et al. 2010). Decreased regulatory activity due to the depletion of Treg cells can result in the production of more IL-12 by DC.

IL-10 is also produced by Treg cells and regulates the production of IL-12 by DC (Gazzinelli et al. 1996, Yanagawa et al. 2008). The drop in IL-10 level after anti$\mathrm{CD} 25 \mathrm{mAb}$ injections might be responsible for the sig- nificant higher production of IL-12 in depleted infected mice. However, it has also previously been described that $\mathrm{CD}^{+} \mathrm{Foxp} 3^{-}$cells that co-produce IFN- $\gamma$ are the primary source of IL-10 during acute toxoplasmosis (Jankovic et al. 2007). Further experiments are required to determine the source of IL-12 and IL-10 in this context.

A significantly greater number of $\mathrm{CD} 4^{+} \mathrm{CD} 25^{+}$cells was observed in the infected mice than in the naïve mice, as previously reported (Couper et al. 2009). This expansion in $\mathrm{CD}^{+} \mathrm{CD}^{2} 5^{+}$cells concerned both Foxp3 ${ }^{+}$ Treg and Foxp3- Teff since the absolute numbers of both populations were found to expand in parallel. The infection also resulted in a significantly greater percentage of Teff cells in spleen and MLN than in naïve mice. Similar findings of an increased expression of $\mathrm{CD} 25^{+} \mathrm{CD} 4{ }^{+} \mathrm{Teff}$ cells have already been reported (Couper et al. 2009).

No significant difference was found in the percentage of Treg cells in spleen or MLN at day 6 p.i. compared to naïve mice, similar to the findings of Tenorio et al. (2011) in resistant mice and contrary to previous reports of a drop in the percentage of Treg cells during acute toxoplasmosis in both susceptible mice (Ge et al. 2008, Oldenhove et al. 2009) and resistant mice (Tenorio et al. 2010).

Changes in Treg/Teff level could be a more informative measure of immune status than absolute Treg numbers as already described (Scholzen et al. 2009). In naïve mice the ratio is greater than in infected mice suggesting an imbalance towards immune inhibition to maintain homeostasis. In infected mice, the ratio is slightly lower consistent with expansion of Teff cells necessary to control the parasite. No significant difference in the Treg/ Teff ratio was found between the two infected groups given anti-CD25 mAb or the control $\mathrm{mAb}$, respectively. This finding is correlated with a comparable susceptibility to the acute infection.

Finally, we conclude that resistance to acute toxoplasmosis in Swiss OF1 mice is accompanied by the maintenance of the percentage of $\mathrm{CD} 4{ }^{+} \mathrm{Foxp} 3^{+} \mathrm{CD} 25^{+}$Treg cells. It is probable that the mortality observed in C $57 \mathrm{BL} / 6$ (susceptible mice), whether after depletion during a sublethal infection (Couper et al. 2009) or from the lethal infection (Oldenhove et al. 2009), might be due to a significant decrease in the Treg/Teff ratio. We hypothesize that a depletion mechanism bringing about a change in the percentage of Treg or Teff cells that significantly alters the Treg/Teff balance in depleted infected mice during acute toxoplasmosis, might cause a significant change in the outcome of the infection.

In addition, we show that the inflammatory phase in Swiss OF1 mice suffering from acute toxoplasmosis is also accompanied by a significant rise in the number and percentage of $\mathrm{CD} 4^{+} \mathrm{Foxp} 3^{-} \mathrm{CD} 25^{+}$Teff cells that become another potential target for anti-CD25 mAb, as already reported in C57BL/6 mice (Couper et al. 2009). Hence the potential effects of anti-CD25 mAb on CD25 nonTreg must be taken into account while using anti-CD25 $\mathrm{mAb}$ as a depletion tool of Treg.

\section{ACKNOWLEDGEMENTS}

To MT Arias, M Mas, S Bigot, T Papin and C Rossignol, for their excellent technical assistance. 


\section{REFERENCES}

Aliberti J, e Sousa CR, Schito M, Hieny S, Wells T, Hu Nagle GB, Sher A 2000. CCR 5 provides a signal for microbial induced production of IL-12 by CD8 alpha ${ }^{+}$dendritic cells. Nat Immunol 1: 83-87.

Belkaid Y 2007. Regulatory T cells and infection: a dangerous necessity. Nat Rev Immmunol 7: 875-888.

Belkaid Y, Piccirillo CA, Mendez S, Shevach EM, Sacks DL 2002. $\mathrm{CD} 4{ }^{+} \mathrm{CD} 25^{+}$regulatory $\mathrm{T}$ cells control Leishmania major persistence and immunity. Nature 420: 502-507.

Couper KN, Blount DG, de Souza JB, Suffia I, Belkaid Y, Riley EM 2007. Incomplete depletion and rapid regeneration of Foxp3 ${ }^{+}$ regulatory $\mathrm{T}$ cells following anti-CD25 treatment in malariainfected mice. J Immunol 178: 4136-4146.

Couper KN, Lanthier PA, Perona-Wright G, Kummer LW, Chen W, Smiley ST, Mohrs M, Johnson LL 2009. Anti-CD25 antibodymediated depletion of effector $\mathrm{T}$ cell populations enhances susceptibility of mice to acute but not chronic Toxoplasma gondii infection. J Immunol 182: 3985-3994.

Curotto de Lafaille MA, Lino AC, Kutchukhidze N, Lafaille JJ 2004. $\mathrm{CD} 25^{-}$cells generate $\mathrm{CD} 25^{+} \mathrm{Foxp}^{+}$regulatory cells by peripheral expansion. J Immunol 173: 7259-7268.

Dubey JP 2008. The history of Toxoplasma gondii - the first 100 years. J Eukaryot Microbiol 55: 467-475.

Finney OC, Riley EM, Walther M 2009. Regulatory T cells in malaria - friend or foe? Trends Immunol 31: 63-70.

Gazzinelli RT, Hayashi S, Wysocka M, Carrera L, Kuhn R, Muller W, Roberge F, Trinchieri G, Sher A 1994a. Role of IL-12 in the initiation of cell mediated immunity by Toxoplasma gondii and its regulation by IL-10 and nitric oxide. J Eukaryot Microbiol 41: 9S.

Gazzinelli RT, Hieny S, Wynn TA, Wolf S, Sher A 1993. Interleukin12 is required for the T-lymphocyte-independent induction of interferon gamma by an intracellular parasite and induces resistance in T-cell-deficient hosts. Proc Natl Acad Sci USA 90: 6115-6119.

Gazzinelli RT, Wysocka M, Hayashi S, Denkers EY, Hieny S, Casper P, Trinchieri G, Sher A 1994b. Parasite-induced IL-12 stimulates early IFN- $\gamma$ synthesis and resistance during acute infection with Toxoplasma gondii. J Immunol 153: 2533-2543.

Gazzinelli RT, Wysocka M, Hieny S, Scharton-Kersten T, Cheever A, Kühn R, Müller W, Trinchieri G, Sher A 1996. In the absence of endogenous IL-10, mice acutely infected with Toxoplasma gondii succumb to a lethal immune response dependent on $\mathrm{CD} 4^{+} \mathrm{T}$ cells and accompanied by overproduction of IL-12, IFN- $\gamma$ and TNFalpha. J Immunol 157: 798-805.

Ge YY, Zhang L, Zhang G, Wu JP, Tan MJ, Hu E, Liang YJ, Wang Y 2008. In pregnant mice, the infection of Toxoplasma gondii causes the decrease of $\mathrm{CD} 4^{+} \mathrm{CD} 25^{+}$-regulatory T cells. Parasite Immunol 30: 471-481.

Grainger JR, Hall JA, Bouladoux N, Oldenhove G, Belkaid Y 2010. Microbe-dendritic cell dialog controls regulatory T-cell fate. Immunol Rev 234: 305-316.

Hisaeda H, Maekawa Y, Iwakawa D, Okada H, Himeno K, Kishihara K, Tsukumo S, Yasutomo K 2004. Escape of malaria parasites from host immunity requires $\mathrm{CD} 4{ }^{+} \mathrm{CD} 25^{+}$regulatory T cells. Nat Med 10: 29-30

Ismael AB, Sekkai D, Collin C, Bout D, Mévélec M-N 2003. The MIC3 gene of Toxoplasma gondii is a novel potent vaccine candidate against toxoplasmosis. Infect Immun 71: 6222-6228.

Jankovic D, Kullberg MC, Feng CG, Goldszmid RS, Collazo CM, Wilson M, Wynn TA, Kamanaka M, Flavell RA, Sher A 2007. Conventional T-bet $\left(^{+}\right)$Foxp3(-) Th1 cells are the major source of host-protective regulatory IL-10 during intracellular protozoan infection. $J$ Exp Med 204: 273-283.
Khan IA, Matsuura T, Kasper LH 1994. Interleukin-12 enhances murine survival against acute toxoplasmosis. Infect Immun 62: 1639-1642.

Kohm AP, McMahon JS, Podojil JR, Begolka WS, DeGutes M, Kasprowicz DJ, Ziegler SF, Miller SD 2006. Cutting edge: anti-CD25 monoclonal antibody injection results in the functional inactivation, not depletion of $\mathrm{CD} 4{ }^{+} \mathrm{CD} 25^{+} \mathrm{T}$ regulatory cells. J Immunol 176: 3301-3305.

Kotner J, Tarleton R 2007. Endogenous $\mathrm{CD} 4^{+} \mathrm{CD} 25^{+}$regulatory $\mathrm{T}$ cells have a limited role in the control of Trypanosoma cruzi infection in mice. Infect Immun 75: 861-869.

Liesenfeld O, Kosek J, Remington JS, Suzuki Y 1996. Association of $\mathrm{CD}^{+} \mathrm{T}$ cell-dependent, interferon- $\gamma$-mediated necrosis of the small intestine with genetic susceptibility of mice to peroral infection with Toxoplasma gondii. J Exp Med 184: 597-607.

Mahnke K, Bedke T, Enk AH 2007. Regulatory conversation between antigen presenting cells and regulatory $\mathrm{T}$ cells enhance immune suppression. Cell Immunol 250: 1-13.

McNeill A, Spittle E, Bäckström BT 2007. Partial depletion of CD69 $9^{\text {low }}$ expressing natural regulatory $\mathrm{T}$ cells with the anti-CD25 monoclonal antibody PC61. Scan J Immunol 65: 63-69.

Morampudi V, De Craeye S, Le Moine A, Detienne S, Braun MY, D'Souza S 2011. Partial depletion of $\mathrm{CD} 4^{+} \mathrm{CD} 25^{+} \mathrm{Foxp}^{+} \mathrm{T}$ regulatory cells significantly increases morbidity during acute phase Toxoplasma gondii infection in resistant BALB/c mice. Microbes Infect 13: 394-404.

Oldenhove G, Bouladoux N, Wohlfert EA, Hall JA, Chou D, Santos LD, O’Brien S, Blank R, Lamb E, Natarajan S, Kastenmayer R, Hunter C, Grigg ME, Belkaid Y 2009. Decrease of Foxp3(+) Treg cell number and acquisition of effector cell phenotype during lethal infection. Immunity 31: 1-15.

Rai D, Pham NL, Harty JT, Badovinac VP 2009. Tracking the total CD8 T cell response to infection reveals substantial discordance in magnitude and kinetics between inbred and outbred hosts. J Immunol 183: 7672-7681.

Robben PM, Mordue DG, Truscott SM, Takeda K, Akira S, Sibley LD 2004. Production of IL-12 by macrophages infected with Toxoplasma gondii depends on the parasite genotype. J Immunol 172: 3686-3694.

Sakaguchi S, Wing K, Onishi Y, Prieto-Martin P, Yamaguchi T 2009. Regulatory T cells: how do they suppress immune responses? Int Immunol 21: 1105-1111.

Scholzen A, Minigo G, Plebanski M 2009. Heroes or villains? T regulatory cells in malaria infection. Trends Parasitol 26: 16-25.

Setiady YY, Coccia JA, Park PU 2010. In vivo depletion of CD4 ${ }^{+}$ Foxp $3^{+}$Treg cells by the PC61 anti-CD25 monoclonal antibody is mediated by FcRII ${ }^{+}$phagocytes. Eur J Immunol 40: 780-786.

Suzuki Y, Orellana MA, Schreiber RD, Remington JS 1988. Interferon- $\gamma$ : the major mediator of resistance against Toxoplasma gondii. Science 4851: 516-518.

Tenorio EP, Fernández J, Olguín JE, Saavedra R 2011. Depletion with PC61 mAb before Toxoplasma gondii infection eliminates mainly Tregs in BALB/c mice, but activated cells in C57BL/6J mice. FEMS Immunol Med Microbiol 62: 362-367.

Tenorio EP, Olguín JE, Fernández J, Vieyra P, Saavedra R 2010. Reduction of Foxp3 ${ }^{+}$cells by depletion with the PC61 mAb induces mortality in resistant BALB/c mice infected with $T$. gondii. $J$ Biomed Biotechnol: e786078.

Waldmann TA 2007. Anti-Tac (daclizumab, Zenapax) in the treatment of leukemia, autoimmune diseases and in the prevention of allograft rejection: a 25-year personal odyssey. J Clin Immunol 27: 1-18.

Yanagawa Y, Iwabuchi K, Onoé K 2008. Co-operative action of interleukin-10 and interferon- $\gamma$ to regulate dendritic cell functions. Immunology 127: 345-353. 


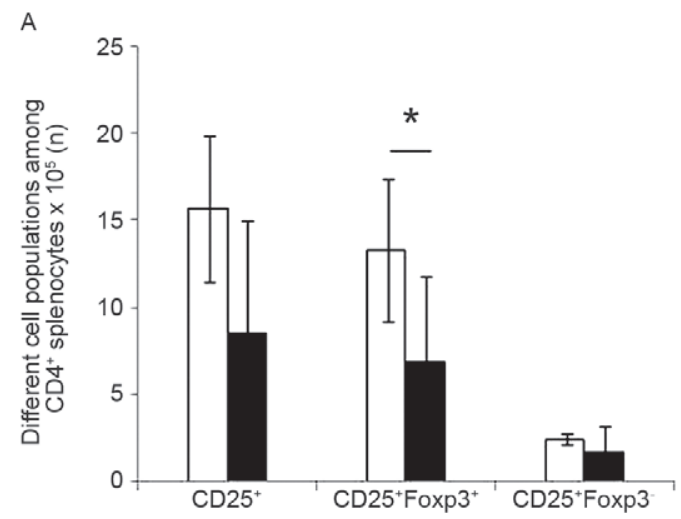

C

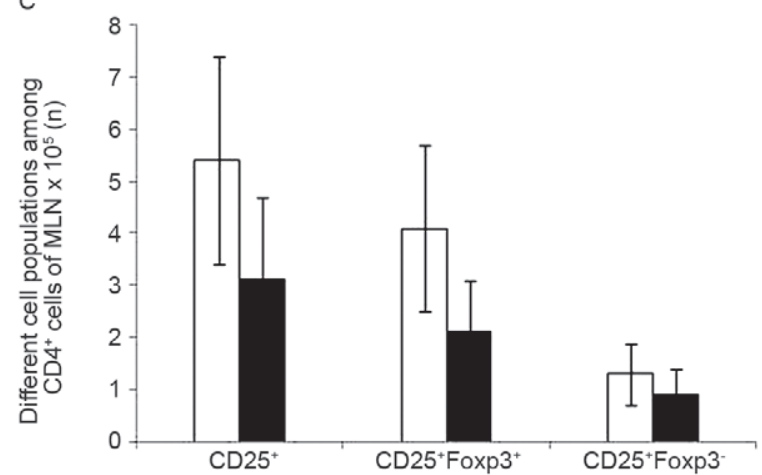

B

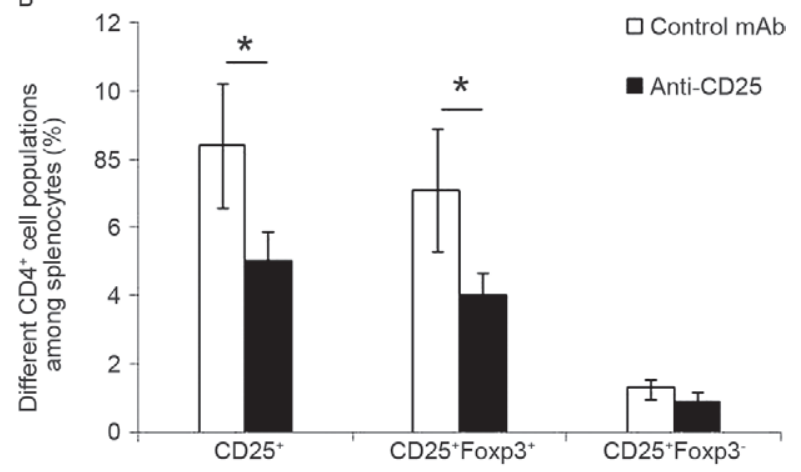

D

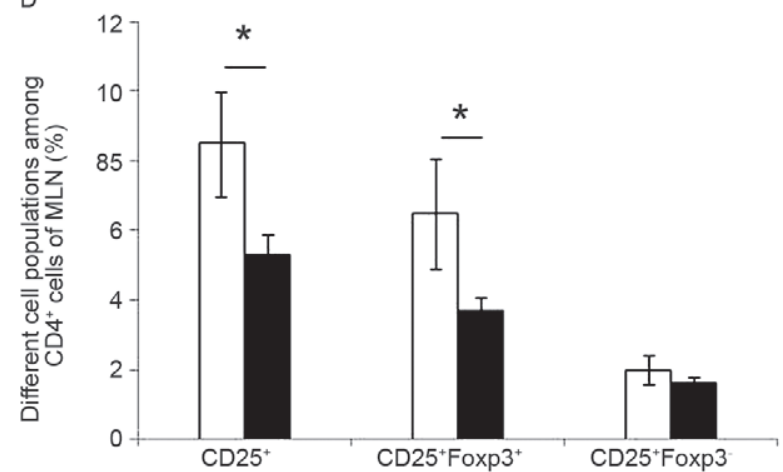

The number and percentage of different cell populations among CD4 $4^{+}$cells of spleen and mesenteric lymph nodes (MLN) three days after last injection of anti-CD25 monoclonal antibody $(\mathrm{mAb})$ or isotype control to non-infected OF1 mice. The graphs represent the average values along with the standard deviations of the total number and percentages of $\mathrm{CD}^{+} \mathrm{CD} 25^{+}$cells, $\mathrm{CD} 4^{+}$forkhead box-p 3 transcription factor (Foxp $3^{+}$) CD25 $5^{+}$regulatory T cells (Treg) and CD4 ${ }^{+}$Foxp3-CD25- effector T cells (Teff) cells in spleen (A, C) and in MLN (B, D). Student $t$ test was used to determine the differences between the two groups. The experience was done once. Asterisk means a significant difference $(\mathrm{p}<0.05)$. $\mathrm{N}=5$ for each group. 